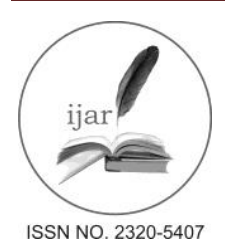

\author{
Journal homepage: http://www.journalijar.com \\ Journal DOI: 10.21474/IJAR01
}

RESEARCH ARTICLE

\title{
MANDIBULAR CANINE AS AID IN GENDER DETERMINANT: A STUDY ON THE POPULATION OF SRINAGAR, KASHMIR, INDIA.
}

\author{
Owais Gowhar', Tasneem S. Ain ${ }^{2}$, Saima Sultan 3 . \\ 1. MDS (Oral Pathology \& Microbiology); Dental Surgeon, Dept Of Dentistry, Govt. J\&K Health \& Family \\ Welfare Department. \\ 2. MDS, Department of Public Health Dentistry; Kothiwal Dental College \& Research Centre, Moradabad, India. \\ 3. MDS, Department of Pedodontics \& Preventive dentistry; Kothiwal Dental College \& Research Centre, \\ Moradabad, India.
}

\begin{abstract}
Manuscript Info
Manuscript History:

Received: 12 April 2016

Final Accepted: 22 May 2016

Published Online: June 2016

Key words:

Forensic Odontology, Canine Index, Gender Determination,

Dimorphism.

*Corresponding Author

Dr. Owais Gowhar drowais83@gmail.com

Abstract

Establishing person's identity is important for both legal and humanitarian purposes. Sex determination is one of the prime factors employed to assist with the identification of an individual. Present study was done to to establish the effectiveness of mandibular canine index in predicting gender in Srinagar, (Kashmir) population. 150 subjects belonging to Srinagar Kashmir population (80 males; 70 females) in the age group of 20-30 yrs were included. Impressions were made with alginate and study models prepared with dental stone. Mesio-distal diameter of mandibular canines and distance between tips of mandibular canines were measured using a Vernier caliper. Mandibular canine index was calculated as the ratio between the maximum mesiodistal width of mandibular canine and canine arc width. Overall, the values obtained for the intercanine distance, right canine width, left canine width, right MCI, and left MCI was found to be significantly higher in males than females and Left canine exhibited greater sexual dimorphism compared with right canine. It is concluded that it is possible to detect gender on basis of canine dimorphism and thus is considered as a quick and easy method for determination of gender of an individual.
\end{abstract}

Copy Right, IJAR, 2016...All rights reserved...

\section{Introduction:-}

In a variety of populations the tooth size has been assessed for applicability in gender determination in anthropology and forensic odontology investigations from dental remnants. ${ }^{1}$ It is mainly based upon the evaluation of tooth dimensions in males and females. ${ }^{2}$ Canines are least affected by periodontal disease and thus less frequently extracted teeth among permanent dentition. Mandibular and maxillary canines due to dimorphism provides evidence of sex determination. ${ }^{3}$ Variations in tooth size may be due to the fact that amelogenesis for both temporary and permanent dentitions in males may be of longer durations. ${ }^{4}$ The present study tries to establishes the importance of the gender factor on the morphometry of the maxillary canines. Previous studies result gives proof that that the dimorphism in maxillary canines can be of immense use in forensic odontology. ${ }^{5}$

Therefore present study was designed to explore the use of mesiodistal width of the mandibular canines, intercanine arch width, and Mandibular Canine Index (MCI) with which gender can be differentiated in population of Srinagar, Kashmir, India. 


\section{Materials and method:-}

A cross sectional study was carried out on 150 individuals residing in Srinagar, Kashmir, India. Of these 80 were males and 70 were females belonging to 20-30 age group. Patients having teeth with Class I canine relationship, healthy periodontium, caries free, attrition free canine teeth were the inclusion criteria and exclusion criteria included patients having carious or missing mandibular anterior teeth, the presence of wasting disease such as abrasion, attrition, midline diastema or spacing, and crowded mandibular anteriors and periodontitis affecting the mandibular anterior teeth.

Verbal consent was taken and alginate was used for Mandibular impressions of all the study samples and then study models were prepared with dental stone. Analysis was done on Mandibular study models.

1. Digital vernier caliper and study cast were used to measure the mandibular canine width.

2. Vernier caliper used were held parallel to the plane of occlusion thus measuring the mesiodistal width of canine

3. Measurement of inter canine distance was also done using vernier caliper.

Mandibular canine width has a direct relationship with the intercanine arch width enabling the Mandibular Canine Index (MCI):

\section{MCI $=\underline{\text { Mesio Distal crown width of mandibular canine }}$}

\section{Mandibular Canine arch width}

\section{Results:-}

The study involved the preparation of 150 plaster casts from 80 males and 70 female participants. The intercanine distance was measured from the cusp tips of right and left mandibular canine using standardized criteria. The results showed that the mean value of the intercanine distance in males was $27.1 \mathrm{~mm}$. In females, the mean value of the intercanine distance was found to be $24.70 \mathrm{~mm}$. The mean value of the width of right canine and left canine as measured using vernier calipers in males was found to be $7.23 \mathrm{~mm}$ and $7.34 \mathrm{~mm}$. The mean value of the width of right canine and left canine in females was found to be $6.32 \mathrm{~mm}$ and $6.42 \mathrm{~mm}$ respectively.

The MCI was calculated using a standardized formula. In males, the MCI on the right side was found to be $0.26 \mathrm{~mm}$ whereas on the left side it was found to be 0.27 . In females, the MCI on the right side was found to be 0.25 whereas on the left side it was found to be 0.25 .

Overall, the values obtained for the intercanine distance, right canine width, left canine width, right MCI, and left MCI was found to be higher in males than females [Graph $1 \&$ Table 1].

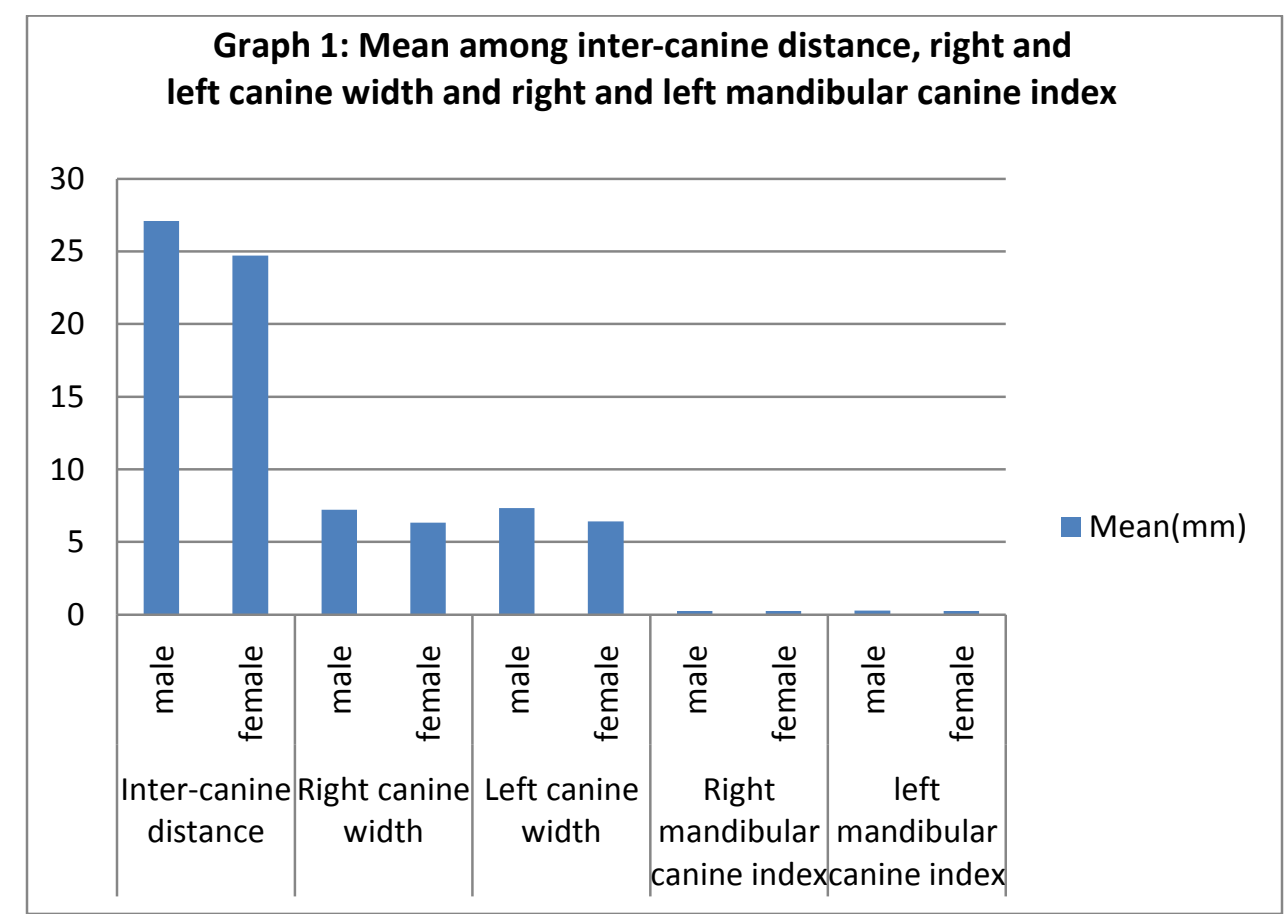




\begin{tabular}{|clc|}
\hline Parameters & Sex & Mean(mm) \\
Inter-canine distance & Male & 27.1 \\
& Female & 24.7 \\
Right canine width & Male & 7.23 \\
& Female & 6.32 \\
Left canine width & Male & 7.34 \\
Right mandibular & Female & 6.42 \\
canine index & & \\
left mandibular canine & & 0.26 \\
index & Male & 0.25 \\
& Male & 0.27 \\
& Female & 0.25 \\
\hline
\end{tabular}

Table1: Mean Values obtained for the intercanine distance, right canine width, left canine width, Right MCI, and Left MCI was found to be higher in males than females

\section{Discussion:-}

Our study ascertains the existence of considerable sexual dimorphism in mandibular canines. This finding is consistent with that of work done by Hashim HA and Murshid ZA ${ }^{6}$, Lew KK and Keng SB ${ }^{7}$. The study proves and establishes that the inter-canine distance and mandibular canine index can be used as useful parameters in differentiating genders in forensic odontology. Y chromosome are responsible mostly in the size of teeth by controlling the thickness of dentine, whereas the $\mathrm{X}$ chromosome plays role in thickness of enamel. ${ }^{8}$ According to Garn SM mandibular canines demonstrate the utmost percentage of sexual dimorphism amongst all teeth in mesiodistal width. ${ }^{9}$

In past Studies done on Saudi males and females found that only the canines in both jaws exhibited a significant sexual dimorphism while the other teeth did not. ${ }^{6}$ Our study is in consistent with these studies done in past on mandibular canines. Similar results were given by Lew and Keng in their study on an ethnic Chinese population with occlusions normal. ${ }^{7}$

Use of odontometric parameters for determination of gender in large population have advantage than ,DNA profiling which gives accurate results, that they are simple, reliable, inexpensive, and easy to measure. Also the fact that most teeth complete development before skeletal maturation makes the dentition a valuable sex indicator, particularly in young individuals. ${ }^{10}$

Canines have a high survival rate then other teeth in dentition and thus have advantage to be used in gender determination by odontometric analysis in forensic odontology. ${ }^{11}$ Mandibular canines are the last teeth to be extracted with respect to age as they are exposed to less plaque, calculus, abrasion or heavy occlusal loading than other teeth and they are also less severely affected by periodontal disease. Hence canines can be termed as wonder tooth in forensic odontology for dental profiling. ${ }^{12}$ The present study has found that mesio-distal diameter was significantly greater in males than females like in other past studies which demonstrated that intercanine distance 
and canine index are valuable parameters as measured in differentiating the genders ${ }^{13}$ and many past studies also stressed that any measurement of teeth unaccompanied by age, race and sex must be treated with great reserve. ${ }^{14}$

Study sample with the age group of 20 to 30 years was included in the present study as early adulthood dentition has less mutilation and attrition in many persons. Therefore can be used for odontometric analysis and therefore the effect of these factors on the actual MD width would be minimum. ${ }^{15}$

\section{Conclusion:-}

From the present study, it can be concluded that Mandibular canine can be used as aid in gender determinant in identification process in forensic odontology. In this study MD width of mandibular canine teeth is greater in male than female in age group 20- 30 years. Mandibular canine arch width is also greater in male than female. Mesiodistal diameter of mandibular canine teeth shows maximum sexual dimorphism among all measurements.

\section{References:-}

1. A. B. Acharya,S. Mainali. Are Dental Indexes Useful In Sex Assessment?. J Forensic Odontostomatol 2008;27:2:53-59.

2. Narang RS, Manchanda A, Singh B. Sex assessment by molar odontometrics in north Indian population. J Forensic Dent Sci. 2015;7:54-8

3. Kiran S. Khaitan TK, Ramaswamy P, Sudhakar S, Smitha B, Uday G. Role of mandibular canines in establishment of gender. Egypt J Forensic Sci 2014;4:71-4.

4. S.Kaushal, G.Patnaik, V.Sood, G.Agnihotri. Sex Determination In North Indians Using Mandibular Canine Index. JIAFM, 2004; 26(2). ISSN 0971-0973.

5. Kaushal, S., Patnaik, V.V.G., Agnihotri, G. Mandibular Canines In Sex Determination. Anat. Soc. India 52(2) 119-124 (2003).

6. Hashim, H.A. and Murshid, Z.A. (1993) : Mesio-distal tooth width - A comparison between Saudi males and females. Egyptian Dental. Journal 39(1): 343-6.

7. Lew KK and Keng SB. Anterior Crown Dimensions and Relationship in an Ethnic Chinese Population with Normal Occlusions. Aust. Orthod. J. 1991; 12 (2): 105-9.

8. Reddy VM, Saxena S, Bansal P. Mandibular canine index as a sex determinant: A study on the population of western Uttar Pradesh. J Oral Maxillofac Pathol 2008;12:56-9.

9. Garn SM, Lewis AB, Swindler DR, Kerewsky RS. Genetic Control of Sexual Dimorphism in Tooth Size. J.Den.Res. 1967; 46:963-972.

10. Narang RS, Manchanda AS, Malhotra R, Bhatia HS. Sex determination by mandibular canine index and molar odontometrics: A comparative study. Indian J Oral Sci.2014;5:16-20.

11. Singh J., Gupta K.D., Sardana V., Balappanavar A.Y., Malhotra G. Sex determination using cheiloscopy and mandibular canine index as a tool in forensic dentistry. J. Forensic Dent. Sci.2012;4(2):70-74.

12. Paramkusam G, Nadendla LK, Devulapalli RV, Pokala A. Morphometric analysis of canine in gender determination: Revisited in India. Indian J Dent Res.2014;25:425-9.

13. Rao N.G and Rao N.N., 1988 Mandibular canine study to establish sex identity in mutilated cadavers. Karnataka State Dental Journal., 6(1): 77-83.

14. Gabriel AC. Some anatomical features of the mandible. Journal of anatomy, 1958; 92(4):580.

15. Sreedhar G, Sumalatha MN, Ramesh G, Nagarajappa R, Murari A, Agrawal A. Dimorphic Mandibular canines in gender determination in Moradabad population of western Uttar Pradesh. J Forensic Dent Sci 2015;7:32-6. 